\title{
UPAYA PENINGKATAN KUALITAS NOMOR DAN KERATAAN ROVING MELALUI STUDI POSISI FLYER CAP PADA MESIN SIMPLEX
}

\author{
Oleh : \\ Asril Senoaji S., Arifin Suadipraja dan Sajinu A.P. \\ Staf Pengajar Sekolah Tinggi Teknologi Tekstil
}

\begin{abstract}
Simplex machine is one from few step process to produce ring spun yarn. This machine has various complex equipments that needs intensive handling and maintenance to keep good performance machine in order to produce high quality roving. Few samples of these complex equipments are trick box to reduce rail step movement (builder motion), cones drum and planetary gear to arrange bobbin winding speed. Beside those complex equipments, there are few little parts of this machine which may potentially reducing roving quality if we could not handle these parts wisely, flyer cap is one of them. Uneven flyer cap position caused by improper installation or deformed part may potentially influencing the number of roving and increasing roving unevenness.
\end{abstract}

\section{INTISAR I}

Mesin Simplex adalah salah satu mesin yang digunakan dalam proses pembuatan ring spun yarn. Mesin pada tahapan ini memiliki berbagai peralatanperalatan kompleks sehingga untuk menghasilkan produk yang berkualitas tinggi diperlukan keahlian dan perhatian yang intensif untuk menjaga performa mesin tetap prima, peralatan kompleks tersebut misalnya : peralatan trick-box yang mengatur gerakan kereta (builder motion), cones drum dan planetary gear yang mengatur kecepatan penggulungan pada bobbin. Selain peralatanperalatan kompleks tersebut pada mesin simplex terdapat bagian kecil yang ternyata apabila tidak diperhatikan dengan baik dapat berpotensi mengurangi kualitas roving yang dihasilkan, bagian kecil tersebut salah satunya adalah flyer cap. Posisi flyer cap miring karena proses pemasangan yang kurang tepat atau rusak (deformed) akan menimbulkan regangan tambahan karena titik tumpu yang dilalui roving pada flyer cap tidak stabil. Hal tersebut dapat berpotensi mempengaruhi nomor dan meningkatkan ketidakrataan pada roving yang dihasilkan.

\section{PENDAHULUAN}

Pada saat ini kita mengenal 2 golongan besar spun yarn yaitu : benang open end yang memiliki karekteristik langsai serta lembut dan benang ring yang memiliki karekteristik kaku serta memiliki kekuaan yang lebih tinggi. E.P.G. Gohl mengatakan bahwa $85 \%$ benang yang yang diproduksi oleh industri adalah 
benang ring, selain dikarenakan permintaan pasar, hal tersebut terjadi dikarenakan faktor penggunaan material (panjang serat dan campuran serat) yang lebih fleksibel dan faktor aplikasi dari benang ring yang dapat dijadikan benang fancy. Kedua jenis benang tersebut dihasilkan dari proses yang berbeda :

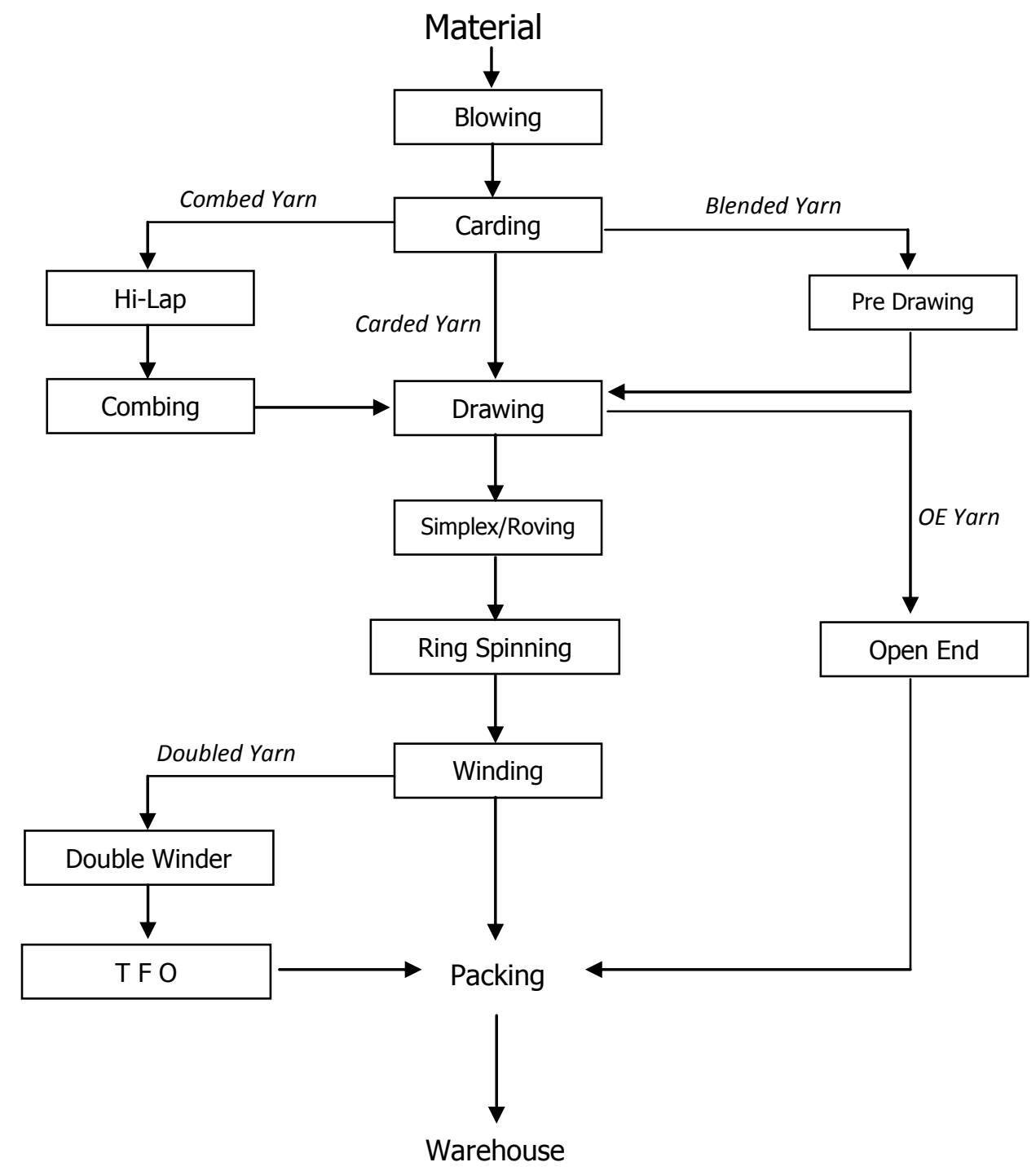

Gambar 1.1. Diagram Alir Pembuatan Benang

Mesin Simplex (Roving) adalah salah satu mesin pada proses pemintalan untuk menghasilkan benang ring, mesin ini berfungsi untuk merubah bentuk sliver menjadi roving melalui peregangan lalu kemudian ditambahkan sedikit antihan untuk meningkatkan kekuatan. Mesin ini multak dibutuhkan pada saat pembuatan benang ring dikarenakan mesin ring spinning yang ada sekarang ini belum mampu melakukan peregangan sekitar $300-500$ kali untuk merubah 
dengan baik sliver hasil mesin drawing menjadi bentuk benang dengan ukuran/nomor yang biasa kita gunakan, karena itu dibutuhkan proses perantara sehingga beban peregangan pada mesin ring spinning dapat dikurangi dan nomor benang yang dihasilkan dapat dicapai dengan baik sesuai dengan yang telah direncanakan.

Mesin simplex memiliki peralatan yang cukup banyak dan kompleks untuk menghasilkan gerakan-gerakan utama dimana kinerja dari peralatan tersebut sangat menentukan kualitas dari roving yang dihasilkan, beberapa contoh peralatan tersebut yaitu:

- $\quad$ Trick-box yang di dalamnya terdapat gigi racet untuk mengatur posisi naik dan turun kereta sehingga membentuk sudut gulungan roving yang proporsional.

- Cones drum dan planetary gear untuk mengatur kecepatan putaran bobbin dan flyer yang semakin lama bergerak semakin lambat seiring dengan penambahan diameter gulungan.

- Beberapa pasang rol peregang yang berputar dalam perbandingan tertentu untuk menghasilkan peregangan dan menentukan besar antihan pada roving yang dihasilkan.

Peralatan tersebut membutuhkan perhatian khusus pada saat mulai pada saat instalasi, setting, operasi dan pemeliharaan. Untuk melakukan hal tersebut dengan baik dibutuhkan skill yang baik dan dengan waktu pengerjaan yang cukup panjang dari bagian maintenance agar hasil proses produksi dapat memiliki kualitas yang tinggi. Namun disamping peralatan tersebut, pada mesin simplex terdapat beberapa peralatan kecil yang apabila posisinya tidak tepat maka akan berpotensi mengurangi mutu dari roving yang dihasilkan, peralatan tersebut salah satunya adalah flyer cap.

Flyer cap adalah bagian dari mesin simplex yang biasanya terbuat dari material karet dan diletakan dibagian atas flyer sebagai jalan masuknya roving yang keluar dari front roll menuju lengan flyer. Flyer cap pada umumnya memiliki permukaan yang halus dengan maksud untuk memimalisasi friksi yang terjadia antara permukaan flyer cap dengan roving, namun ada beberapa flyer cap yang memiliki kontur beralur pada daerah tertentu dengan tujuan untuk menghasilkan grip yang optimum untuk mendukung pada proses pemberian antihan pada roving. Flyer cap akan berputar bersamaan dengan putaran flyer pada saat mesin berkerja, hal ini disebabkan karena flyer cap dipasang menempel pada flyer top. 


\section{Simplex}

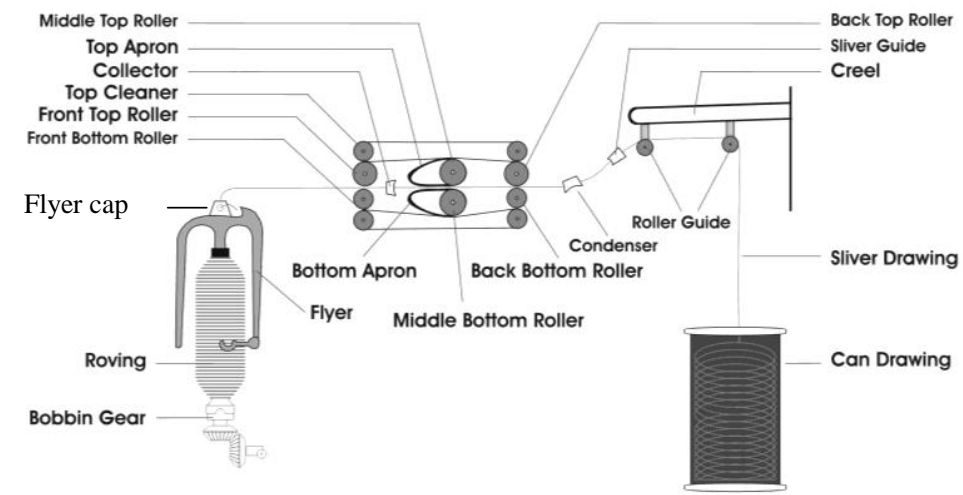

Gambar 1.2. Skema Mesin Simplex

Proses pemasangan flyer cap tidaklah terlalu sulit dan tidak membutuhkan waktu yang lama dengan cara menempatkan pada posisi yang tepat lalu memberikan tekanan agar flyer cap tersebut dapat terpasang dengan sempurna pada flyer top. Flyer cap yang terpasang dengan rata akan berputar dengan posisi stabil mengikuti putaran flyer. Meskipun proses instalasinya cukup mudah, penulis hingga saat ini masih menemukan posisi flyer cap yang tidak tepat pada mesin simplex di beberapa industri pembuatan benang padahal hal tersebut dapat berpotensi menurunkan kualitas roving yang dihasilkan seperti laiknya apabila ada kerusakan pada peralatan-peralatan besar dan komplek pada mesin simplex ini. Posisi flyer cap yang tidak tepat ini dapat disebabkan karena kesalahan pada saat instalasi, terkena benturan, pengaruh getaran mesin atau karena kerusakan bagian flyer cap itu sendiri.

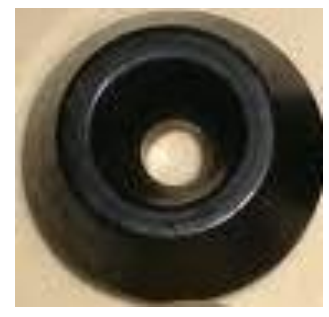

Flyer cap pandangan atas.

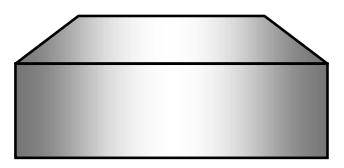

Flyer cap pandangan samping

Gambar 1.3. Gambar Flyer Cap

Pada tahun 1983, telah dilakukan penelitian terkait dengan pengaruh pemakaian dua jenis flyer cap pada mesin simplex tipe FL-16 terhadap mutu benang yang dihasilkan pada mesin ring spinning tipe RY di PT KTSM oleh Achmad Nurhassan Dadi dan pada kesempatan ini penulis bermaksud melakukan penelitian terkait dengan posisi flyer cap untuk meningkatkan mutu khususnya pada nomor dan kerataan dari roving yang dihasilkan. 


\section{BAHAN, ALAT DAN METODE}

Bahan yang digunakan dalam percobaan ini adalah sliver drawing cotton carded $\mathrm{Ne}_{1} 0.128$ dengan kualitas yang memenuhi standar khususnya ketidakrataan dan nomor. Bahan baku ini kemudian diproses dengan menggunakan Mesin Simplex Toyoda FL-16 dengan menggunakan setting tertentu sehingga dapat menghasilkan roving dengan nomor $\mathrm{Ne}_{1}$ 0.88. Bentuk flyer cap pada mesin Simplex Toyoda FL-16 apabila dilihat melalui pandangan atas menyerupai 'donat' (lingkaran dengan lubang pada bagian tengahnya sebagai tempat masuknya roving) dan apabila dilihat melalui pandangan samping berbentuk trapesium, seluruh permukaan flyer cap dibuat halus untuk mengurangi friksi pada saat dilalui oleh roving ketika mesin berkerja.

Metode percobaan ini dilakukan dengan membandingkan roving hasil head dengan posisi flyer cap rata dan roving hasil head dengan posisi flyer cap miring. Penulis menggunakan 10 buah head yang kemudian dibagi dua dalam 2 kelompok yaitu : Kelompok A (head 1-5) yang pada counter 0-1290 meter flyer capnya dipasang rata dan Kelompok B (head 6-10) yang pada counter 0-1290 meter flyer capnya dipasang miring. Setelah memasuki counter 1291-2000 meter posisi flyer cap pada kedua kelompok tersebut ditukar dari yang awalnya posisi rata menjadi posisi miring dan sebaliknya, hal ini dimaksudkan untuk meminimalisasi faktor lain yang dapat mempengaruhi hasil percobaan (seperti: getaran mesin diawal dan akhir doffing) selain faktor posisi flyer cap. Pada saat percobaan berlangsung, tidak ada perubahan material dan setting pada mesin kecuali posisi flyer cap sehingga variasi yang terjadi pada roving yang dihasilkan diharapkan hanya dipengaruhi oleh posisi flyer cap semata. Untuk mempermudah proses percobaan, penulis menentukan kondisi posisi flyer cap miring ini hanya dibatasi pada posisi flyer cap dengan kemiringan kurang-lebih $30^{\circ}$ terhadap cover bagian atas mesin simplex .

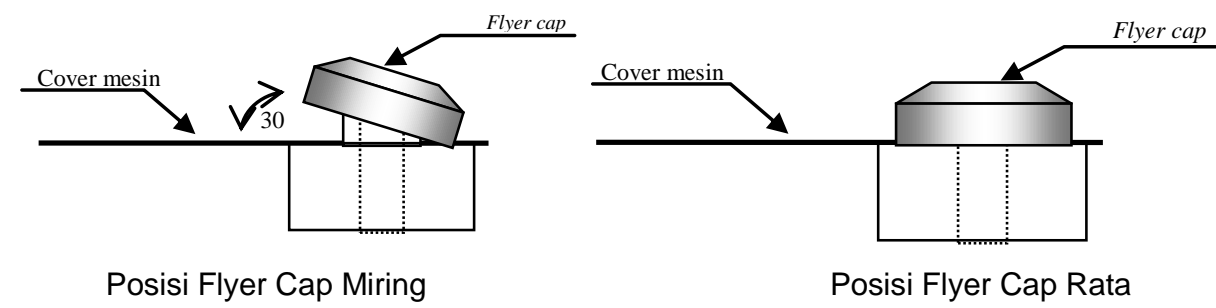

Gambar 1.4. Posisi Flyer Cap 
1. Nomor Roving

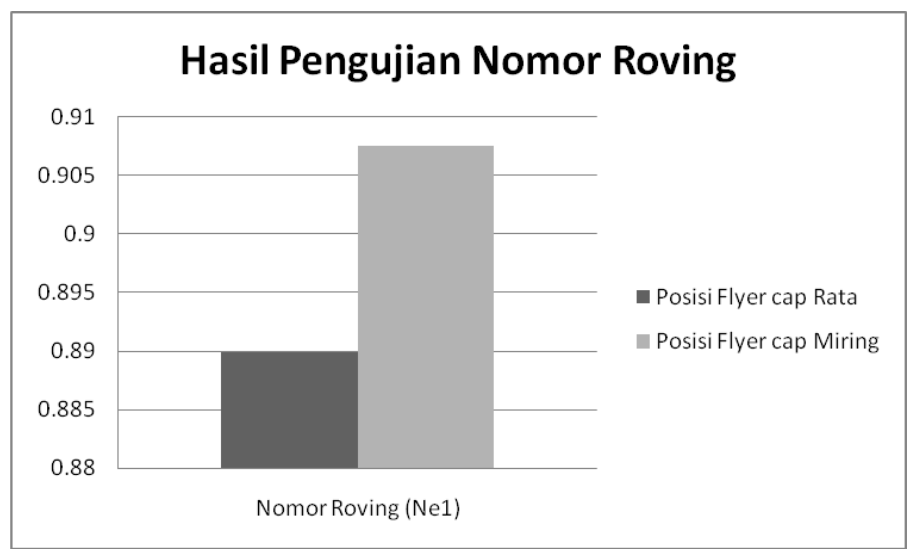

Target nomor roving yang diinginkan dalam proses ini adalah $\mathrm{Ne}_{1} \quad 0,8800$. Berdasarkan data hasil percobaan diketahui bahwa nomor roving yang dihasilkan oleh head dengan posisi flyer cap miring lebih tinggi dibandingkan dengan nomor roving yang dihasilkan dari head dengan posisi flyer cap rata. Nomor roving yang dihasilkan oleh head dengan posisi flyer cap miring yaitu : $\mathrm{Ne}_{1}$ 0,9075 sedangkan nomor roving yang dihasilkan dari head dengan posisi flyer cap rata adalah $\mathrm{Ne}_{1} 0,8899$.

Salah satu hal yang menjadi penyebab peristiwa ini adalah timbulnya peristiwa peregangan tambahan pada daerah diantara front roll dengan flyer cap pada head dengan posisi flyer cap miring. Salura mengatakan bahwa salah satu peristiwa yang dapat menimbulkan drafting adalah "melalui perantaraan dua titik jepit yang dimana satu titik jepit tetap dalam posisinya (stasionir) sedangkan titik jepit lainnya berpindah tempat (mobil)". Setelah mengalami peregangan pada front roll, roving akan bergerak menuju lengan flyer melalui titik tumpuan pada bagian atas lubang flyer cap. Pada head dengan posisi flyer cap miring, front roll pada mesin roving adalah titik jepit stasionir yang tetap pada tempatnya sedangkan titik tumpuan yang dilintasi oleh roving pada bagian atas lubang flyer cap miring adalah titik jepit mobil yang bergerak. Seperti kita ketahui bersama bahwa flyer cap akan ikut berputar seiring dengan putaran flyer. Di head dengan posisi flyer cap miring, titik tumpuan yang dilalui roving pada bagian atas lubang flyer cap bergerak berputar menjauhi dan kemudian kembali mendekati front roll. Peristiwa tersebut terjadi berulang-ulang selama mesin bekerja. Sesuai dengan pernyataan Salura maka roving yang keluar dari front roll akan mengalami regangan tambahan setelah keluar dari front roll menuju flyer cap. Regangan inilah yang kemudian menyebabkan nomor roving yang dihasilkan oleh head dengan posisi flyer cap miring menjadi lebih tinggi. 


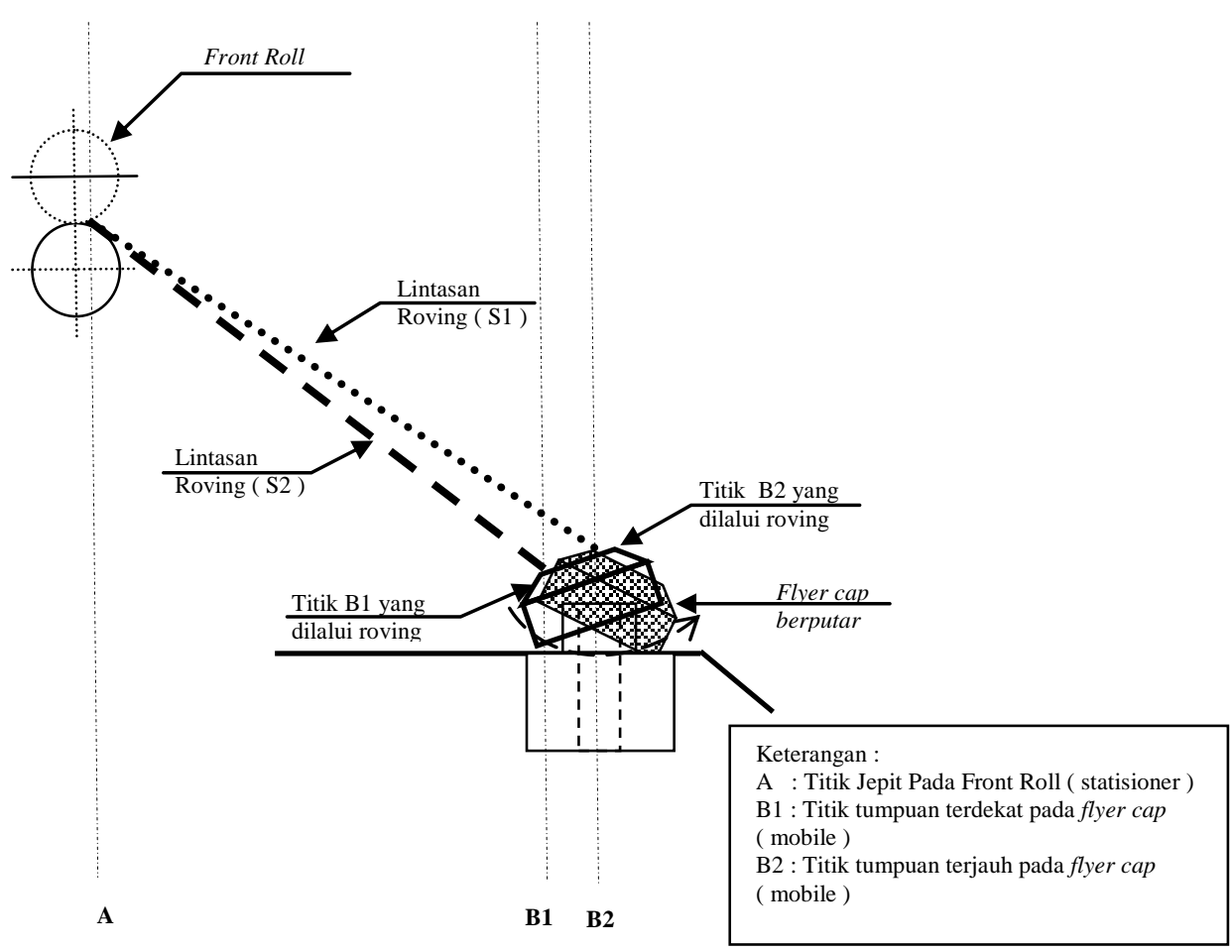

Gambar 3.1. Skema Lintasan Roving Pada Flyer Cap Miring

Pada head dengan posisi flyer cap rata, posisi front roll tidak bergerak (stasioner) dan titik tumpuan yang dilintasi roving pada lubang bagian atas flyer cap cenderung tetap (stasioner) sehingga dapat dikatakan tidak ada regangan tambahan pada daerah ini. Dengan demikian nomor roving yang dihasilkan cenderung lebih mendekati target nomor roving yang diinginkan karena dapat dikatakan peregangan seolah-olah hanya terjadi pada drafting zone diantara rolrol peregang.

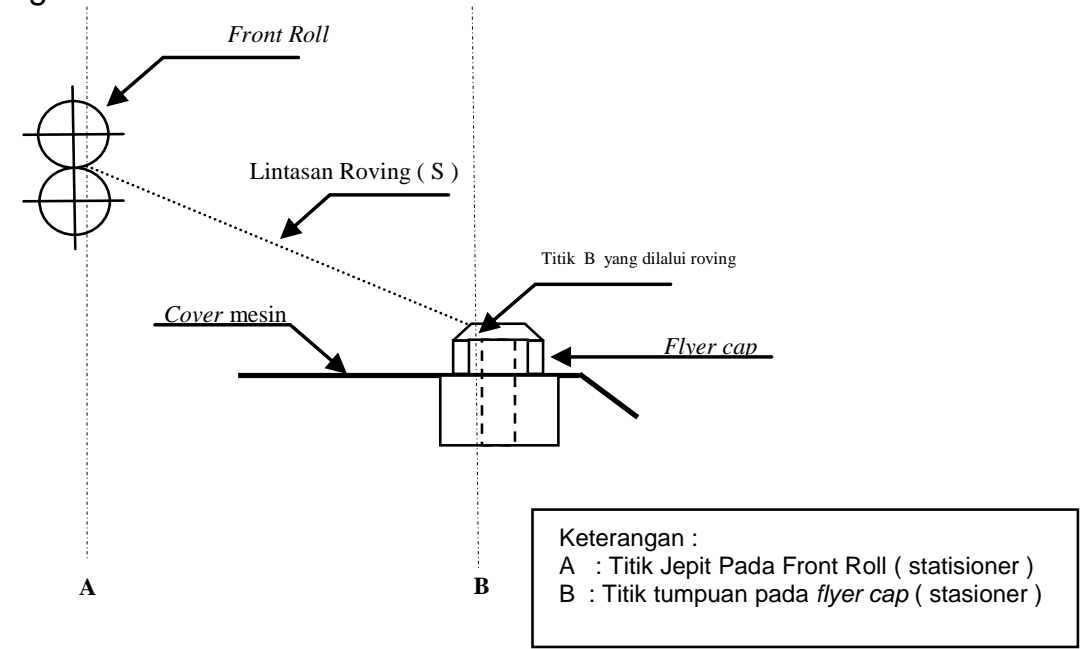

Gambar 3.2. Skema Lintasan Roving Pada Flyer Cap Rata 


\section{Ketidakrataan Roving}

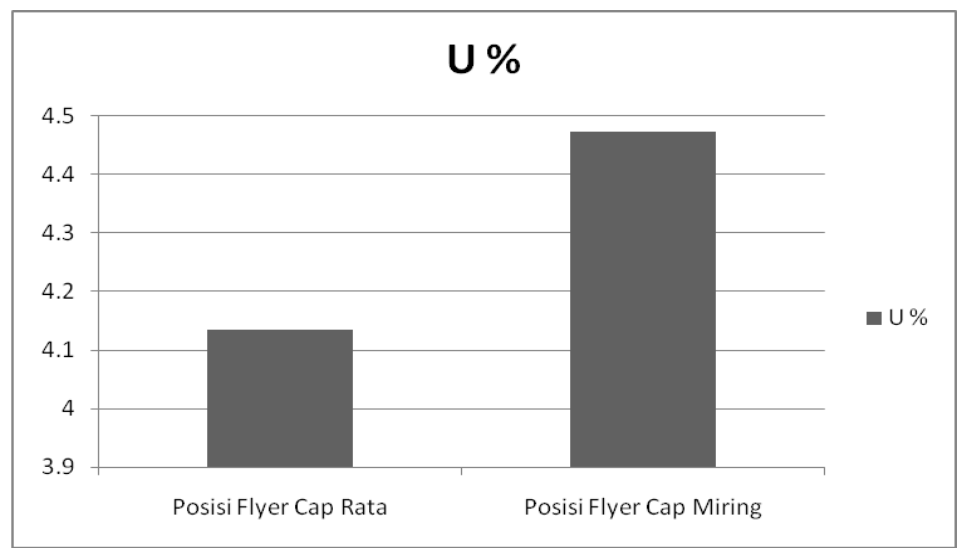

Berdasarkan data hasil percobaan diketahui bahwa nilai ketidakrataan dari roving yang dihasilkan oleh head dengan posisi flyer cap miring lebih tinggi $(4,472 \%)$ dibandingkan dengan roving yang dihasilkan oleh head dengan posisi fyler cap rata $(4,134 \%)$. W.Klein dalam bukunya yang berjudul The Technology Of Short Staple Spinning mengatakan bahwa setiap proses peregangan akan mengarah terhadap peningkatan ketidakrataan.

Pada mesin simplex, proses peregangan dilakukan pada daerah diantara rol-rol peregang yang berjumlah 3-4 pasang. Pengaturan besar nilai peregangan dapat ditentukan melalui perubahan roda gigi draft change wheel dan seyogianya hanya terjadi pada daerah tersebut meskipun pada realitanya pada bagian lain juga berpotensi terjadi peregangan pada roving. Pada percobaan ini, dengan asumsi semua kondisi sama kecuali posisi flyer cap, roving yang dihasilkan oleh head dengan posisi flyer cap miring mengalami peregangan lebih banyak dibandingkan roving yang dihasilkan oleh head dengan posisi flyer cap rata. Seiring dengan pendapat W.Klein tersebut maka tingkat ketidakrataan dari roving yang dihasilkan oleh head dengan posisi flyer cap miring akan lebih tinggi dibandingkan dengan roving yang dihasilkan oleh head dengan posisi flyer cap rata.

\section{KESIMPULAN}

Berdasarkan hasil percobaan dan pembahasan dapat kita ketahui bahwa bagian kecil pada mesin simplex dapat mengurangi kualitas dari roving yang dihasilkan apabila bagian maintenance atau operator kurang memberikan perhatian yang cukup. Kita dapat menjaga kualitas nomor dan kerataan roving yang dihasilkan melalui pengaturan posisi flyer cap yang tepat. 
Dengan demikian, hal ini perlu ditegaskan dalam SOP Operator dan Maintenance Mesin Simplex agar senantiasa memperhatikan kondisi dan posisi flyer cap pada mesin simplex untuk menjaga kualitas dari roving yang akan dihasilkan.

\section{DAFTAR PUSTAKA}

1. Instruction Manual for High Speed Simplex Fly Frame Model FL-16 ( $9^{\text {th }}$ edition), 7.6.6 Notice on Cleaning Flyer cap.

2. E.P.G. Gohl, Textiles For Modern Living (fifth edition), Longman Cheshire, Australia, 1993.

3. Pawitro, S. Teks., Teknologi Pemintalan Bagian Kedua, Institut Teknologi Tekstil, Bandung, 1975.

4. Salura, Teori Draft dan Ketidakrataan Benang, Institut Teknologi Tekstil, Bandung, 1972.

5. W. Klein, The Textile Institute, The Technology of Short Staple Spinning, England, 1987.

6. www.textiletechinfo.com/spinning/ROVINGFRAME.htm 